\title{
Differences and similarities between kraft and oxygen delignification of softwood fibers: effects on mechanical properties
}

\author{
Cláudia V. Esteves $(\mathbb{D})$ Olena Sevastyanova $(\mathbb{B} \cdot$ Sören Östlund $(\mathbb{D})$ \\ Elisabet Brännvall
}

Received: 1 December 2020/Accepted: 16 February 2021 / Published online: 27 February 2021

(C) The Author(s) 2021

\begin{abstract}
Charged groups in pulp have been shown to enhance the tensile strength of the paper produced from the pulp. Oxygen delignification introduces charged groups and it is of interest to determine how the delignification should be distributed between the cooking and the oxygen stage with respect to mechanical properties. A number of unbleached kraft cooked and oxygen delignified pulps within a wide kappa number range were produced and refined, and the effects of the refining on the morphology and mechanical properties were studied. The WRV correlated with the fiber charge and at a given fiber charge, kraft cooked and oxygen delignified pulps had the same WRV development in refining, although they
\end{abstract}

Supplementary Information The online version contains supplementary material available at https://doi.org/10.1007/ s10570-021-03781-2.

C. V. Esteves $(\bowtie) \cdot$ E. Brännvall

RISE INNVENTIA AB, Drottning Kristinas väg 61,

11428 Stockholm, Sweden

e-mail: claudia.esteves@ri.se

E. Brännvall

e-mail: elisabet.brannvall@ri.se

O. Sevastyanova

Department of Fiber and Polymer Technology, KTH

Royal Institute of Technology, 10044 Stockholm,

Sweden

e-mail: olena@kth.se had significantly different kappa numbers. The tensile strength development during refining depends on the fiber rigidity which is affected by the lignin content, the fiber charge and the chemical and mechanical processes used. Refining increased the curl of the kraft cooked pulps and decreased the curl of oxygen delignified pulps, irrespective of kappa number. A greater increase in tensile strength was seen for the pulps with a higher fiber charge and WRV, probably because of the greater degree of fibrillation achieved in the beating process. Despite the greater fiber deformation in the oxygen delignified pulps, the strength can be increased by a larger amount of charged groups and a greater swelling of the fibers. 


\section{Graphic abstract}

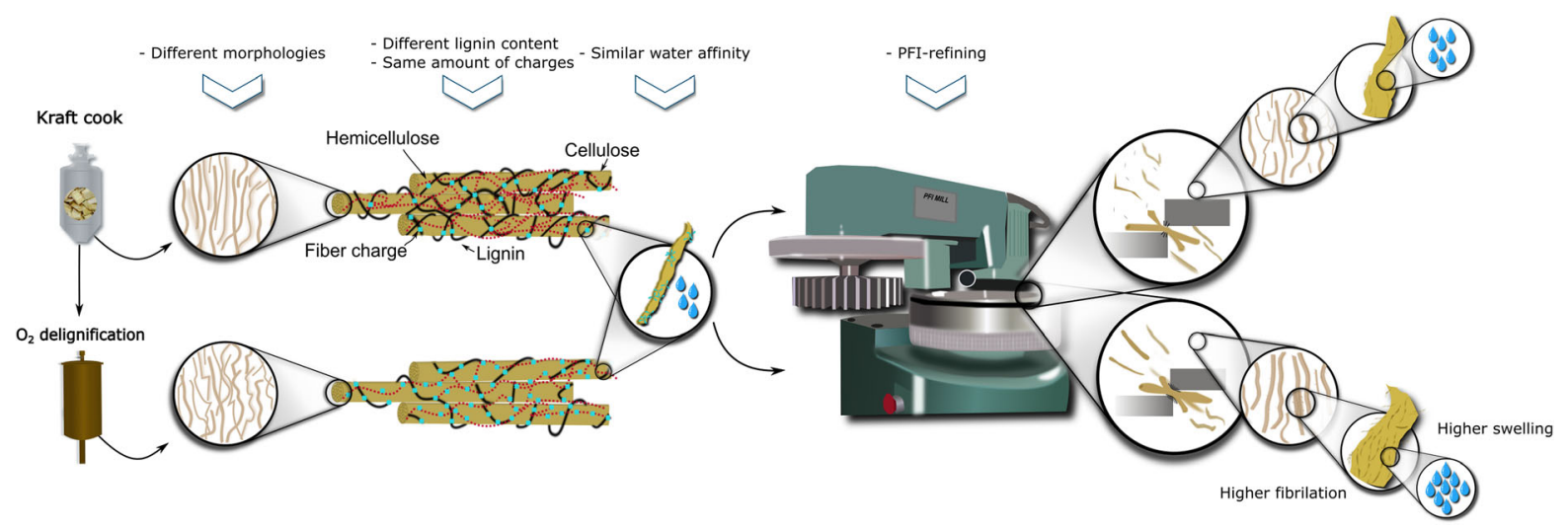

Keywords Strength · Bonding · Curl index · Swelling $\cdot$ Refining $\cdot$ Fibrillation $\cdot$ Conformation

\section{Introduction}

Paper strength and the mechanisms contributing to the strength of the joints between fibers have been extensively studied over the years. Several mechanisms such as mechanical entanglement of fibrils and interdiffusion of polymers, electrostatic interactions and van der Waals forces have been mentioned but the contribution of each of these is not yet fully understood (Campbell 1959; Hirn and Schennach 2015; Retulainen 1997; Schmied et al. 2013). The inter-fiber joints in the paper network are known to be the most important factor for tensile strength (Ingmanson and Thode 1959), and the hydrogen bonds between the hydroxyls groups in cellulose and hemicelluloses are known to contribute to the inter-fiber bonding, although only $2 \%$ of the hydroxyl groups are able to form such bonds (Paavilainen 1994; Van den Akker et al. 1958). Beating is one of the processes that contributes significantly to the paper strength by increasing the fiber surfaces able to form hydrogen bonds. Besides the increase in the amount of fiber surfaces created by internal and external fibrillation and fines, beating also increases fiber flexibility and fiber conformability, and increases the water retention capacity (Page 1985). Fibrillation and the production of fines contribute to an increase in surface tension, known as the Campbell effect, and promote bonding (Paavilainen 1994). The conformability of the fibers is influenced by both the fiber swelling capacity and the refining process (Hammar et al. 2000). The greater swelling ability caused by the beating facilitates the formation of stronger fiber-fiber joints (Engstrand et al. 1991). The swelling ability of the fibers before the beating process also is very important, as the swelling contributes to a more extensive surface fibrillation (Ingmanson and Thode 1959). Charged carboxylic groups located on the carbohydrates and lignin contribute to fiber swelling, leading to an expansion of the fiber structure within and outside the fiber wall, due to the concentration gradient created by the osmotic pressure (Wågberg 2009). This expansion breaks the intra-fiber bonds and the swelling continues until an equilibrium is reached (Scallan 1983).

The importance of charged groups for the joint and network strength has also been recognized in the literature (Dang et al. 2006; Esteves et al. 2020; Hirn and Schennach 2015; Laine and Stenius 1997; Yang et al. 2003; Zhang et al. 2005, 2007; Zhao et al. 2016). It is known that oxygen delignification increases fiber charges and it apparently makes a much more important contribution to the final paper properties than was previously realized. Combinations of conditions in the oxygen delignification process have the potential to exert unique effects on the fiber morphology leading to improved paper strength properties (Esteves et al. 2020; Yang et al. 2003; Zhao et al. 2016). The swelling of refined fibers is extremely 
important, affecting the area available for bonding (Campbell 1959).

Fiber morphology also has a great impact on the mechanical properties (Mohlin et al. 1996). The morphology can depend on the raw material or on the process to which fibers are subjected. In this work, the raw material was the same, so that any morphological differences will be due solely to the processes, the chemical pulping, the beating, and the bleaching processes. An increase in fiber deformations such as curls and kinks has also been reported after oxygen delignification of kraft cooked pulps, and it has been pointed out that these lead to a reduction in tensile strength (Mohlin et al. 1996; Yang et al. 2003). Subsequent beating seems to be able to remove large parts of the fiber deformation, and the strength properties are then restored to the values for the undeformed pulp (Mohlin and Alfredsson 1990; Mohlin et al. 1996; Rauvanto and Henricson 2009).

In this paper, the response to refining of pulps obtained after kraft cooking and oxygen delignification is discussed. The refining of unbleached fibers is not commonly studied; however, it would be important to understand its impact in order to comprehend the following procedures and fiber modifications. In our previous work (Esteves et al. 2020), it was concluded that charged groups enhance the development of tensile strength during refining. Cooked and oxygen delignified pulps with similar chemical compositions were compared, and it was shown that the mechanical strength could be increased by oxygen delignification if the fiber charge level was sufficiently high. The aim of the present study is to compare the results of delignification over a broad kappa number range with only kraft cooking and with a combination of kraft cooking and oxygen delignification, in order to assess how the delignification should best be distributed between kraft cooking and oxygen delignification from a mechanical point of view.

\section{Material and methods}

Material

A mixture of softwood chips with $70 \%$ Spruce (Picea abies) and 30\% Pine (Pinus sylvestris), from BillerudKorsnäs Skärblacka was used in this study.
Methods

\section{Kraft cooking and oxygen delignification}

Kraft cooking was performed at a temperature of $160{ }^{\circ} \mathrm{C}$ with $30 \%$ sulfidity and a liquor/wood ratio of 4.5 1/kg (Table S1 in SI). Oxygen delignification was carried out at a temperature of $100{ }^{\circ} \mathrm{C}$ and a pressure of $0.7 \mathrm{MPa}$, and the alkali charge and time were varied (Table S2 in SI). A detailed description is given in Esteves et al. (2020).

\section{Refining}

Pulps were beaten to four different levels (500, 100, 2000, 4000 revolutions) in a PFI-mill in accordance with ISO 5264-2.

\section{Paper making}

Hand sheets with a grammage of $60 \mathrm{~g} / \mathrm{m}^{2}$ were prepared in accordance with ISO 5269-1.

Analysis of pulp and paper properties

The water retention value (WRV) was determined according to SCAN-C 62:00 and calculated as

$W R V=\frac{m_{1}-m_{2}}{m_{2}}$,

where $m_{1}$ is the mass of wet fibers after centrifugation and $m_{2}$ is the mass of the dry fibers.

The drainage resistance measured as the SchopperRiegler number was determined according to ISO 5267-1.

The kappa number was measured according to ISO 302:2004. The carbohydrate composition was determined according to SCAN-CM 71:09. All the tests were performed in duplicate.

\section{Fiber charge measurements}

The total fiber charge was determined by conductometric titration according to the method described by Katz et al. (1984). 


\section{Fiber morphology}

L\&W Fiber Tester equipment was used to evaluate the fiber morphology. A digital imaging system takes picture of the fibers in an aqueous suspension that is subjected to a strong flow in order to transport and orientate them. These images were used to obtain the fibers parameters using a standard software. The curl index was calculated from the shape factor, related to the highest percentage of fibers with lengths between 1.5 and $3 \mathrm{~mm}$, according to Page et al. (1985) as

Curl Index $(\%)=\frac{1}{\text { shape factor }}-1$,

The measurements were made in duplicate for each pulp sample at different refining levels.

\section{Structural and mechanical tests}

The grammage was determined according to ISO 536 and the structural thickness according to SCAN-P 88:01. Tensile tests were carried out according to ISO 1924-3. All the measurements were made in a controlled room at $23{ }^{\circ} \mathrm{C}$ and $50 \%$ relative humidity.

\section{Results and discussion}

The purpose of this study was to investigate how delignification by kraft cooking and by oxygen delignification affects the refinability and strength properties of softwood pulp. Pulps with different kappa numbers were produced by kraft cooking or by kraft cooking followed by oxygen delignification, as shown in Fig. 1. The pulps were designated by $\mathrm{Kx}$ when only kraft cook was used and by Kx_Oy when oxygen delignification was carried out after the kraft cook. The final kappa number achieved in each case is indicated by the numbers $\mathrm{x}$ and $\mathrm{y}$.

Fiber charges: effect on swellability

Fiber swelling leads to significant changes in the fiber wall. It can increase the conformability and decrease stiffness, leading to a larger contact area between the fibers and promoting their bonding. It is also claimed that swelling can cause debonding and separation of the microfibrils and lamellae, making the cell structure more loose and leading to an increase in fiber flexibility (Laine and Stenius 1997; Scallan 1983).

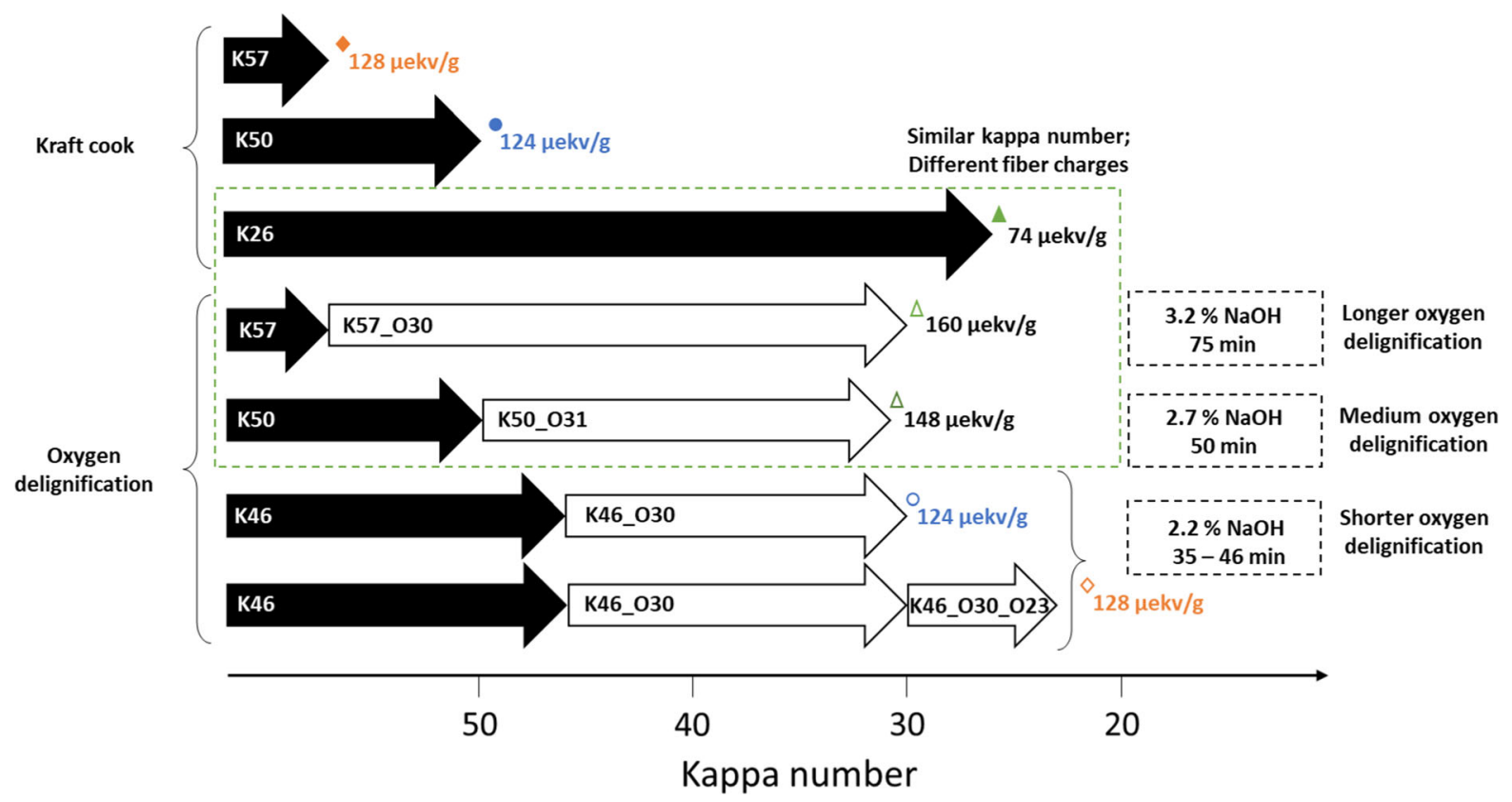

Fig. 1 Schematic presentation of the kraft cooking and oxygen delignification. The length of the arrows shows the degree of delignification. The total fiber charges are presented in the right end of the arrow with different symbols (Diamond represents
$124 \mu \mathrm{ekv} / \mathrm{g}$ for K57 and K46_O30_O23, Circle represents 124 $\mu \mathrm{ekv} / \mathrm{g}$ for K50 and K46_O30 and Triangle represents different fiber charges but similar kappa numbers) 

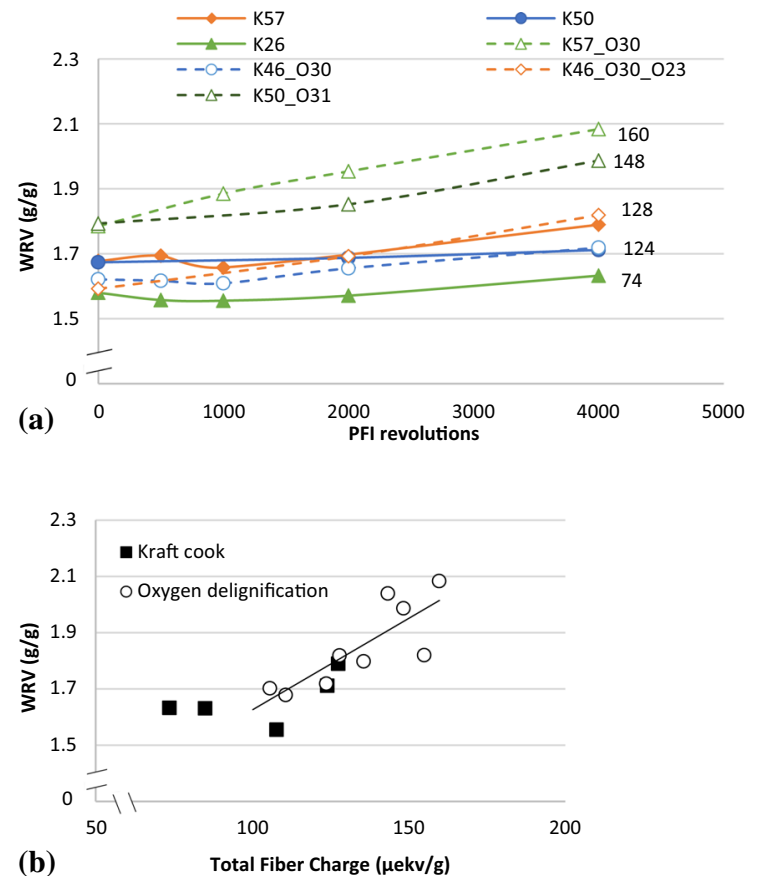

Fig. 2 a Effect of refining on the development of WRV. The pulps with a total charge of $128 \mu \mathrm{ekv} / \mathrm{g}$ are represented by the orange lines and those with $124 \mu \mathrm{ekv} / \mathrm{g}$ by the blue lines. The green lines correspond to samples with a similar kappa number (26, 30 and 31) but different fiber charges. b WRV at 4000 PFI revolutions as a function of total amount of charged groups

Figure 2(a) shows the development of WRV during the refining process. The increase in WRV was dependent on the amount of charged groups in the pulp. The green data sets show the highest $(160 \mu \mathrm{ekv} /$ $\mathrm{g}$, continuous line) and lowest (74 $\mu \mathrm{ekv} / \mathrm{g}$, dotted line) amounts of charged groups. These two pulps had similar chemical compositions (Table 1), but the pulp with the highest amount of charged groups had been oxygen delignified to kappa number 30 (K57_O30) while the other was delignified solely by kraft cooking to kappa number 26 (K26). The pulp with the highest amount of charged groups had the highest WRV value in the unrefined state, and refining increased the WRV significantly, whereas the pulp with the lowest amount of charged groups started at a low WRV level and refining hardly affected the WRV. K57_O30 and K50_O31, had similar kappa numbers but different fiber charges, and K50_O31, with the lower fiber charge, had a slightly slower WRV development than K57_O30.

In Fig. 2, the high dependence of WRV on the amount of charged groups in the pulp is seen. Figure 2(a) shows two sets of pulp having the same amount of charged groups, two with $128 \mu \mathrm{ekv} / \mathrm{g}$ (orange) and two with $124 \mu \mathrm{ekv} / \mathrm{g}$ (blue). The effect of refining on the WRV was similar for these pulps and the WRV was between those of the pulps of highest and lowest amount of charged groups, although, the pulps with charge contents of 128 and $124 \mu \mathrm{ekv} / \mathrm{g}$ varied significantly in lignin content, as shown in Table 1. Pulps with $128 \mu \mathrm{ekv} / \mathrm{g}$ were either cooked to kappa number 57 or oxygen delignified to kappa number 23 and pulps with $124 \mu \mathrm{ekv} / \mathrm{g}$ were either cooked to kappa number 50 or oxygen delignified to kappa number 30. Another difference is the location of the charged groups. In the cooked pulps, charges derive mainly from methyl glucuronic or hexenuronic groups on the xylan backbone. In the case of the oxygen delignified pulps, however, carboxyl groups have been created on the lignin structure. Despite the large difference in lignin content and in the location of the charged groups, the WRV of pulps with same amount of charged groups showed a similar response to refining.

Table 1 Chemical composition and fiber charges of the kraft cooked and oxygen delignified pulps

\begin{tabular}{lllllll}
\hline Sample & Kappa no & Xylan & (Galacto-) Glucomannan & Cellulose & Lignin & Total fiber charge $(\mu \mathrm{ekv} / \mathrm{g})$ \\
\hline K57 & 57 & 8.23 & 8.12 & 72.11 & 11.54 & 128 \\
K50 & 50 & 8.46 & 8.27 & 74.67 & 8.61 & 124 \\
K26 & 26 & 8.57 & 8.42 & 77.88 & 5.13 & 74 \\
K57_O30 & 30 & 8.39 & 8.18 & 77.93 & 5.50 & 160 \\
K50_O31 & 31 & 8.41 & 8.32 & 77.48 & 5.79 & 148 \\
K46_O30 & 30 & 8.21 & 8.53 & 77.33 & 5.94 & 124 \\
K46_O30_O23 & 23 & 8.51 & 9.21 & 77.92 & 4.38 & 128 \\
\hline
\end{tabular}


Figure 2(b) shows the WRV after 4000 refining revolutions as a function of the total amount of charged groups for all the pulps. The WRV correlated fairly well with fiber charge. Mohlin (2002) showed that charged groups affect the refining process and Bäckström et al. (2013) also showed that the beating of pulps with a high fiber charge results in an extreme increase in fiber swelling ability.

Fiber charge: effect on refinability and mechanical properties

The tensile strength was not, however, dependent on the fiber charge, Fig. 3(a). This was shown previously, for a limited kappa number range, 25-30 (Esteves et al. 2020). With increasing refining, the tensile index increased but there was no correlation between tensile strength and WRV, although, the pulp with the highest charge, $160 \mu \mathrm{ekv} / \mathrm{g}$, had the highest tensile index. Although the bonding properties are normally increased by an increase in fiber charge, there was no clear correlation between them, c.f. Laine and Stenius (1997).

The tensile strength was similar for all the unrefined pulps despite a significant difference in WRV, Fig. 3(b). In general, refining of the kraft cooked pulps had a minor effect on the WRV, whereas refining of oxygen delignified pulps, especially those with a high charge, resulted in an increased in both tensile index and WRV. This may be because in cooking, the fibers remain in a wood matrix whereas in oxygen delignification, they are separated and when subjected to alkali and high temperature the consequences on the structure might make them easier to swell. It thus appears that an increase in WRV due to fiber charges cannot affect the mechanical properties without a further refining step.

The tensile strength is affected by the degree of pulp swelling. The increase in cell wall plasticity associated with the higher degree of swelling leads to a larger bonded area as the contact area between fibers increases (Scallan and Grignon 1979), but the extent of fiber swelling is restricted by the fibrillar structure of the fiber wall layers. It has however been shown by Lindström and Carlsson (1982) that if the fiber charges are significantly increased, the swelling forces can overcome these restraining forces and the fibers can swell much further. For this to happen, the fiber charges should be distributed uniformly and evenly in
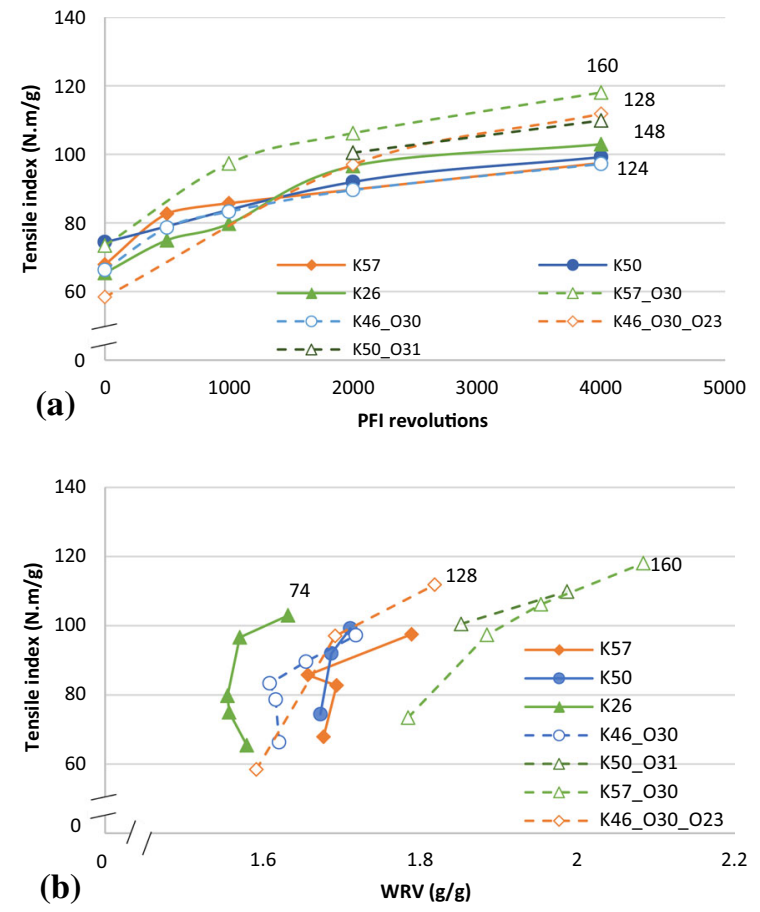

Fig. 3 a The tensile index as a function of the extent of refining. The amount of total charges $(\mu \mathrm{ekv} / \mathrm{g}$ ) is given to the right of the curves; $\mathbf{b}$ Tensile index as a function of WRV

the fiber wall, leading to an overall fiber swelling. This increase in volume, increases the internal and external fibrillation, leading to a stronger bonding by the creation of a larger bonded area (Fig. 4). If the charges are clustered and not uniformly distributed in the fiber wall, the swelling and bonding potential is not as efficient.

The hypothesis that fibrillation is increased by the increase in fiber volume is supported by the results of previous studies where the beating process was improved by the greater swelling of fibers in the $\mathrm{Na}^{+}$form (Bäckström et al. 2013; Mohlin 2002). External fibrillation may increase the mechanical interlocking mechanism that can increase tensile strength 30 to $55 \%$ for pulps beaten to a very high number of revolutions (Clark 1969; Motamedian et al. 2019; Schmied et al. 2013).

Although the lignin content did not affect the development of WRV during refining, the conformability of the fibers was affected by the lignin content. Sheets made from pulps with the highest kappa numbers, K50 and K57, had the lowest density throughout the refining (Fig. 5(a)), which was not unexpected since fibers with a high lignin content are 


\begin{tabular}{|c|c|c|c|}
\hline \multicolumn{2}{|c|}{ Regular fiber charge } & \multicolumn{2}{|c|}{ Higher fiber charge } \\
\hline $\begin{array}{c}\text { Non-beaten } \\
\text { fiber }\end{array}$ & Beaten fiber & $\begin{array}{c}\text { Beaten fiber } \\
\text { with higher WRV }\end{array}$ & $\begin{array}{l}\text { Beaten fiber with } \\
\text { much higher WRV }\end{array}$ \\
\hline
\end{tabular}
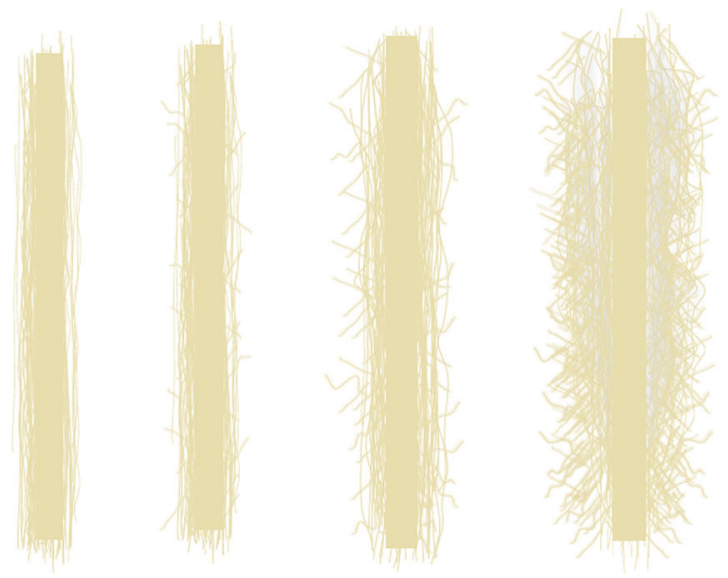

- Much higher external fibrillation;

- Higher conformability;

- Higher collapsibility;

Fig. 4 Effect of refining on fibers with normal and much higher swelling
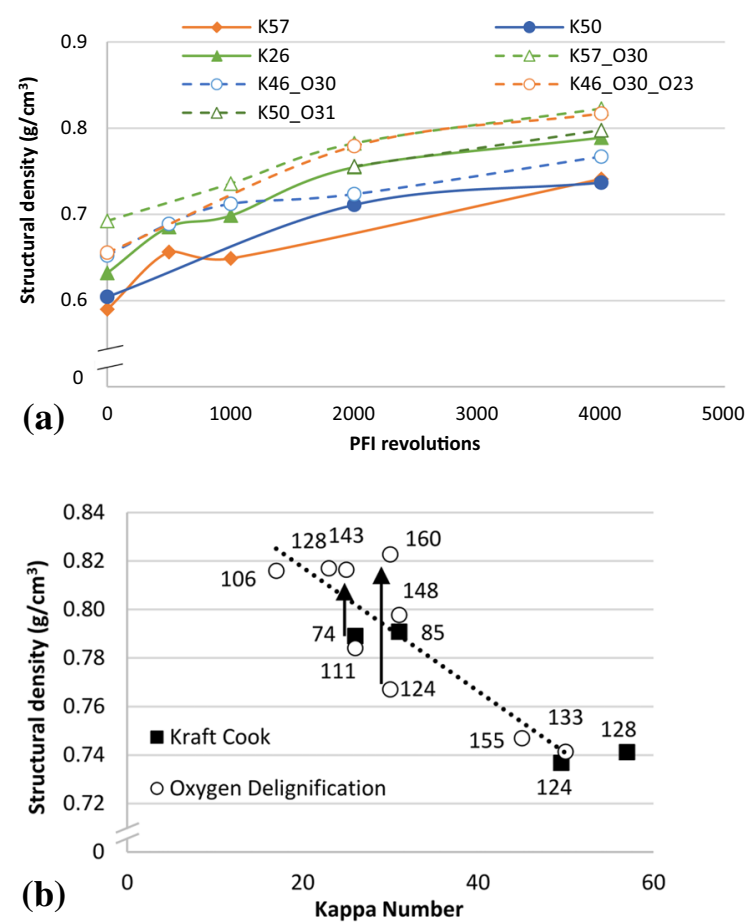

Fig. 5 a Effect of refining on the development of sheet density b Structural sheet density of pulps refined at 4000 revolutions as a function of the kappa number. The numbers beside the data points are the amount of total charges $(\mu \mathrm{ekv} / \mathrm{g})$ stiffer. The effect of lignin content on densification is shown in Fig. 5(b), where the density of sheet made of pulps after $4000 \mathrm{PFI}$ revolutions is shown to decrease with increasing kappa number.

In the case of the oxygen delignified pulps, the higher fiber charge and greater swelling led to a better flexibility and conformability of the fibers, as previous reported by Engstrand et al. (1991) and Laine (1997). Figure 5(b) shows the effect of kappa number on the structural density, where the charge density values are also given. The fiber charge seems to have no effect below a threshold point. At a given kappa number, the density was higher for the oxygen delignified pulps that had significantly higher fiber charges (arrows). When the difference in fiber charge was less than $70 \%$, the density was the same or even lower (Fig. 5(b)). The fiber charges are located on different chemical components depending on whether they are in kraft cooked or oxygen delignified pulp. The surface fiber charge is known to have a greater importance for the bonding strength (Barzyk et al. 1997; Zhang et al. 2007; Zhao et al. 2016), but in our studies it seemed to make only a weak contribution.

Figure 6(a) shows a clear correlation between tensile index and sheet density for the individual pulps, but different tensile index levels were obtained 
for the different pulps, especially at low densities. The tensile index value at a given sheet density was higher for pulps with a higher lignin content. This was also reported by Nordström (2014), where a higher kappa number gave a higher tensile index at a given low density. It appears that less bonded area is required to reach a given tensile index for pulps with a high lignin content. The tensile strength of paper is not determined by the strength of the fibers but rather by the strength of their joints. At kappa numbers as high as 50 and 57, the kraft cooked fibers are bulkier and less collapsed than fibers with less lignin, creating a less densified sheet while achieving a good joint strength between fibers.

For the pulp with the highest total fiber charge, (K57_O30), the density was significantly higher even before the refining. The higher WRV and better conformability of the fibers given by the improved fibrillation resulting from the beating process can lead to a stronger fiber network structure. It has previously been shown that fibers with a high internal integrity (higher lignin and less mechanical processes/steps) show a greater resistance to expansion and therefore less swelling development (Stone et al. 1971). After the individualization of the fibers by defibration process after kraft cook they may be more susceptible to subsequent treatment (Esteves et. al. 2021).

The relationship between tensile stiffness index and the structural density was similar for all the pulps, except for the pulp with the lowest kappa number, Fig. 6(b). When subjected to oxygen delignification in two stages, K46_O30_O23, this pulp had a lower tensile stiffness value at a given sheet density than the other pulps. For the pulps with a high kappa number (K57 and K50), the tensile stiffness index was, as expected, higher for the non-beaten pulps since their higher lignin content leads to a higher stiffness.

Fiber charge: effect on drainage resistance

The Schopper-Riegler value (SR) increased with increasing beating, the extent of the increase varied, as shown in Fig. 7(a). The cooked pulps had a lower water drainage resistance than the oxygen delignified pulps with a higher fiber charge, but no direct correlation could be seen between the fiber charge and the SR value (Fig. 7).

Although K57 and K46_O30_O23 had similar WRV values due to the same amount of fiber charge
(Fig. 2(a)), Fig. 7(a) shows that they had different SR values indicating that K46_O30_O23 had a larger amount of fines.

The dewatering of the pulps is related to the fiber morphology, fiber fibrillation, and fines content. Fibrils and fines have a greater swelling ability and the fines fill the spaces between the fibers leading to a slower dewatering (Motamedian et al. 2019). The removal of fines from pulps with extremely high charges has been shown to lower the WRV, but the amount of fines created by beating was lower than expected in the case of highly charged fibers (Bäckström et al. 2013). In the present study, the amount of fines was not determined, but Fig. 7(b) suggests that the increase in SR was greater in the pulps with higher fiber charges, in the case of the pulps with the same kappa number (K46_O30 and K57_O30) this can be because the production of fines or fibrils during the beating process was intensified by the increase in swelling.

\section{Refining: effect on curl index and number of kinks}

The morphological features of the delignified fibers were studied by the L\&W Fiber Tester, to kappa numbers from 57 to 17 .

The refining process affects the structure of the fibers due to the mechanical forces to which they are subjected. Fibrillation creates new surfaces in the fibers, delamination of the cell wall and the formation of fines (Laine 1997; Page 1989). This has a great impact on the final paper properties and it is also known to decrease fiber deformation (Joutsimo et al. 2005; Mohlin and Alfredsson 1990; Page 1985), but the cooked pulps and oxygen delignified pulps behaved differently. PFI refining has been shown to straighten fibers (Mohlin and Alfredsson 1990; Page 1985), as seen here for oxygen delignified pulps, but in the present case, the deformation of the cooked pulp increased as a result of the refining (Fig. 8) as was also reported by Esteves et al. (2020), and Nordström (2015). Even though PFI refining does not fully reproduce the same results as in the industry refiners, it gives important information about the fibers behavior and its impact on their morphology. The PFI-mill provides a much more homogeneous treatment while in industrial refiners some fibers can remain unbeaten.

The pulps subjected to a kraft cook with the highest kappa number (K57 and K50) had the lowest curl 

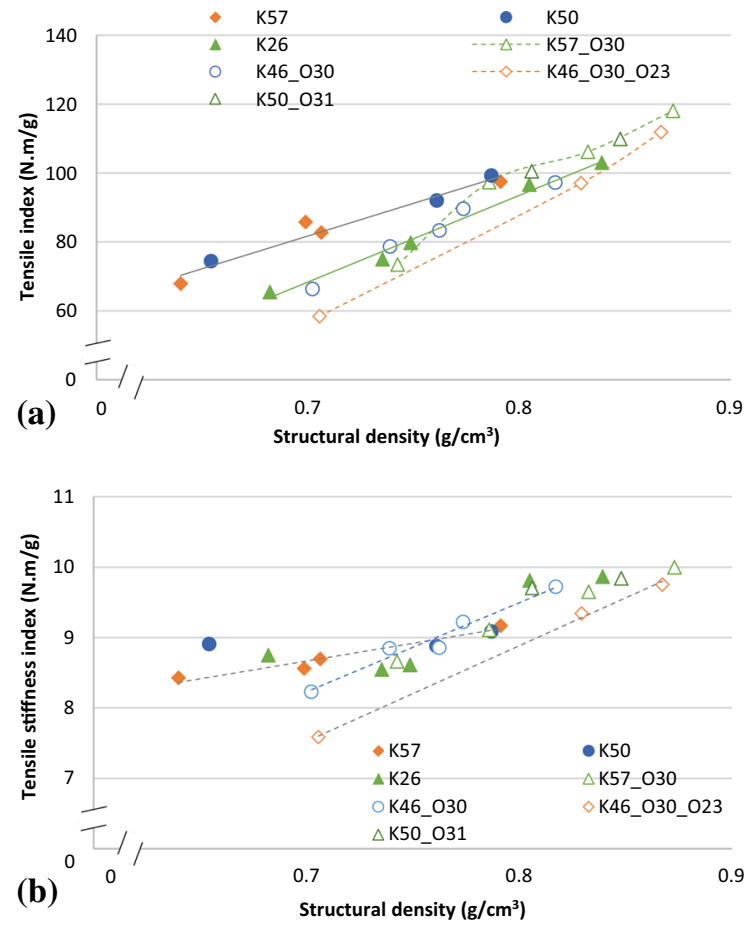

Fig. 6 a Tensile index vs. sheet density and $\mathbf{b}$ tensile stiffness index vs. sheet density for pulps after cooking and/or oxygen delignification to different kappa numbers

index and the refining resulted in a minor increase in the curl (Fig. 8(a)), which is in accordance with the densification shown in Fig. 6(a). The pulps with the highest kappa number were more rigid, and they showed less tendency to curl than the pulps with the lower kappa number, where the fiber wall is weakened due to the removal of chemical components. Page (1989) reported that low yield pulps tend to curl more than high yield pulps.

In contrast, the oxygen delignified pulps presented a higher curl index for non-beaten pulps, and the curl index decreased with increasing number of PFI revolution until stabilized after 2000 revolutions (Fig. 8(b)). These fibers were more flexible and therefore easier to straighten in the beating process. The higher swelling capacity also contributes to a straightening of the fibers.

Cooked pulps have had less mechanical treatment than oxygen delignified pulps. If the pulps after a kraft cook are stiff and rigid, the refining process will tend to lead to more deformation in the fibers, leading to an increase in curl and potential damage due to the mechanical action during beating (Fig. 8(a)). On the other hand, the pulps that have been oxygen delignified have been subjected to additional mechanical treatments so they are more flexible, and their greater swelling capacity will help the refining process to straighten the fibers (Niskanen 2000) and at the same time make the structure more ductile/plasticized. (Fig. 8(b)).

The initial difference in curl between the unrefined kraft cooked and oxygen delignified pulps seems to be lost in the beating process for pulps with a kappa number higher than 40 (Fig. 9(a)). The curl index observed after $4000 \mathrm{PFI}$ revolutions is very similar for pulps from both processes, although the oxygen delignified pulps always showed fewer defects such as curl and kinks. Although oxygen delignification is known to introduce deformations in the fibers, these pulps had fewer deformations than the cooked pulps
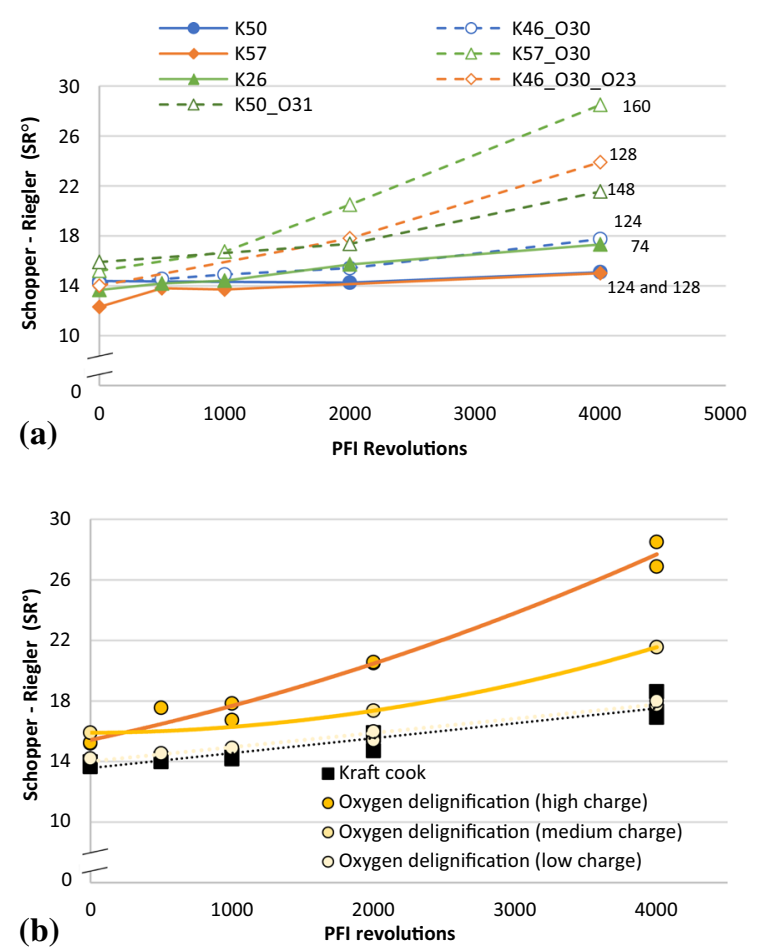

Fig. 7 a Effect of refining on the development of the SchopperRiegler value. The amount of total charges $(\mu \mathrm{ekv} / \mathrm{g})$ is given to the right in the figure, where $128 \mu \mathrm{ekv} / \mathrm{g}$ is represented by the orange lines and $124 \mu \mathrm{ekv} / \mathrm{g}$ by the blue lines. The green lines correspond to samples with similar kappa numbers but different fiber charge. b Schopper-Riegler value for kraft cooked and oxygen delignified pulps with different amounts of charged groups and similar kappa numbers (25 to 32 ) 


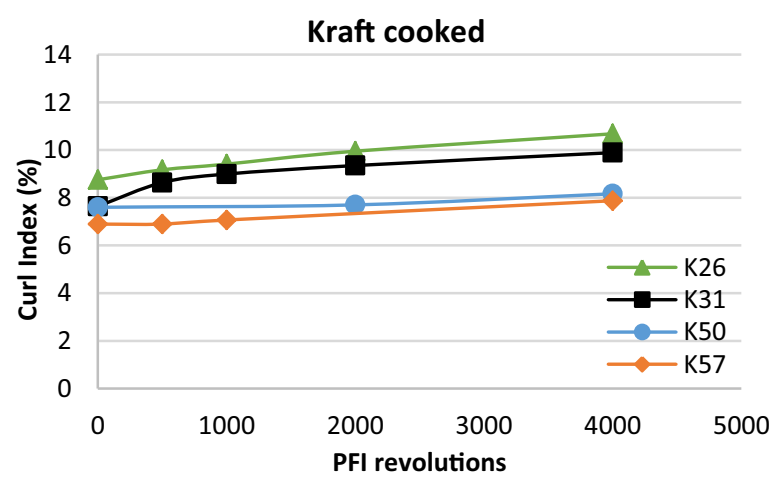

(a)

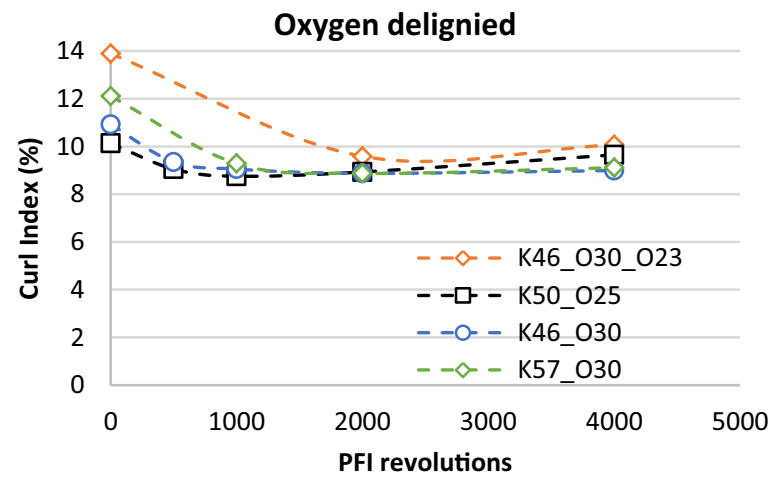

(b)

Fig. 8 Curl index as function of PFI revolutions in a specific fiber length range from 1.5 to $3 \mathrm{~mm}$ for $\mathbf{a}$ kraft cooked pulps and $\mathbf{b}$ oxygen delignified pulps

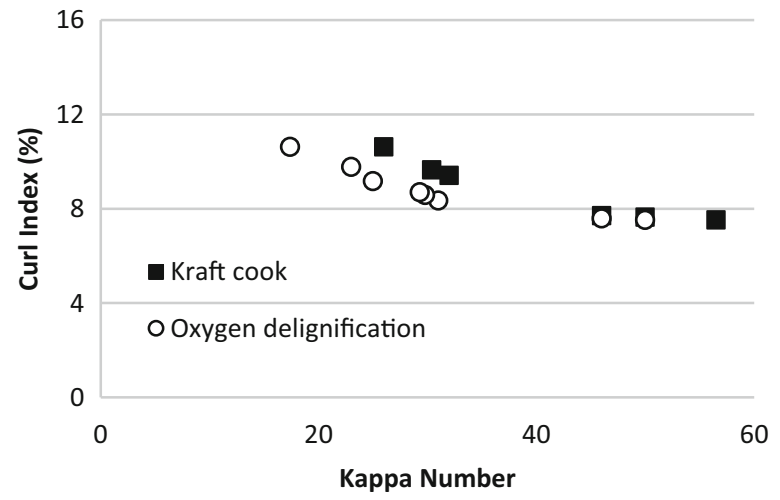

(a)

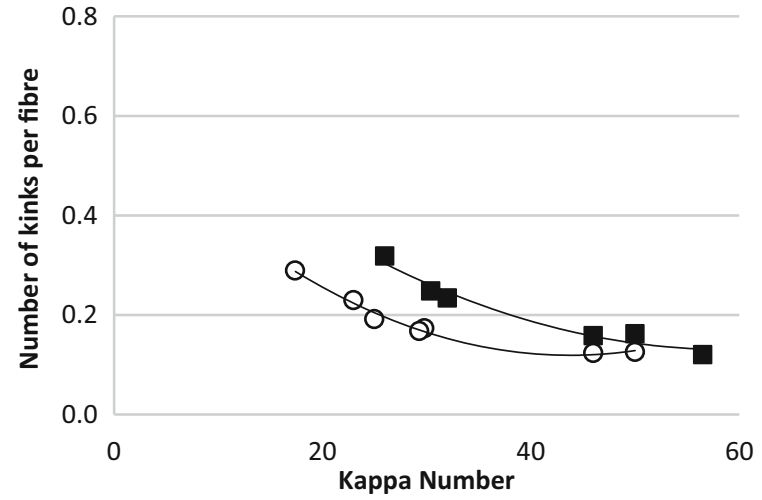

(b)

Fig. 9 a Curl index for fibers with fiber length between 1.5 and $3 \mathrm{~mm}$ and $\mathbf{b}$ number of kinks per fiber for pulp beaten at 4000 revolutions

after the mechanical beating process. This leads to the conclusion that the mechanical actions and deformations introduced by the oxygen delignification process may improve the fiber flexibility and help the fibers to profit more from the refining process. The rigidity and non-vulnerability of the kraft pulps leads to more kinks per fiber than in oxygen delignified pulpsFig. 9(b).

Pulps with a high lignin content are expected to have weak inter-fibers joints due to their poor hydrogen bonding ability, but Fig. 6(a) shows that the high kappa number pulps (K57 and K50) from kraft cooking had a higher tensile strength at a lower density, than the other pulps. The curl index for these pulps was low and did not change during the beating process-Fig. 8(a). This means that the fibers were straighter and stiffer, possibly with a larger bonding area, achieving a higher strength by their contact area and their large content of lignin.

Curl index: effect on mechanical properties

An important negative effect of a high curl index is a decrease in tensile strength of the paper (Joutsimo et al. 2005; Mohlin et al. 1996; Page et al. 1985). Figure 10 illustrates this effect for both low and high degrees of refining. The behavior seems to be the same regardless of whether the process is kraft cooking or oxygen delignification.

The strain at break can be also affected by fiber deformation as shown in Fig. 11(a). For non-beaten pulps, the strain at break increased with increasing curl index, but for beaten pulps all the samples had similar strain at break values. 


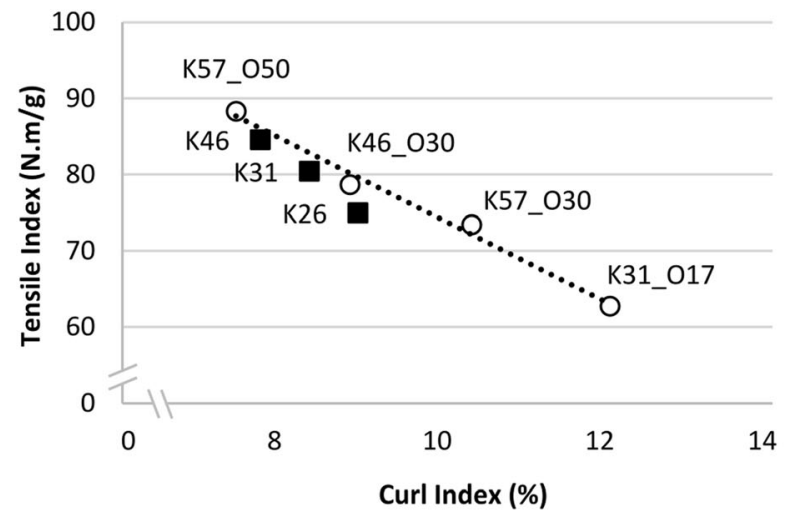

(a)

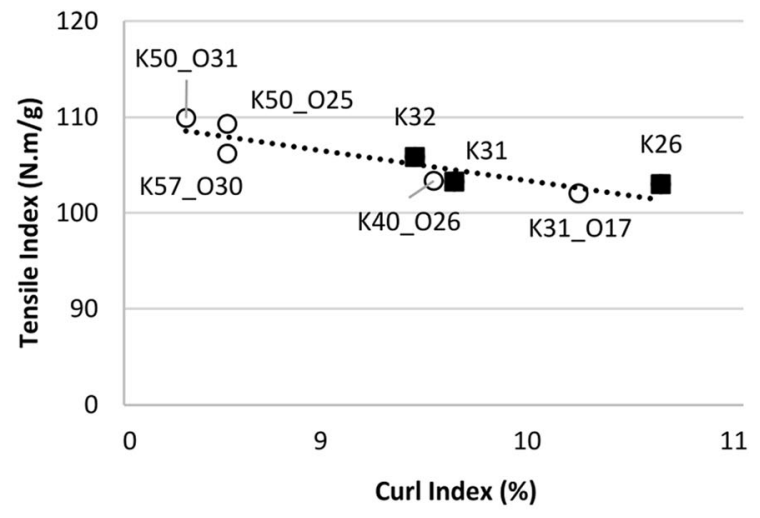

(b)

Fig. 10 Curl index effect on the tensile index for pulps a with a low beating level (density of approximately $0.69 \mathrm{~g} / \mathrm{cm}^{3}$ ) and $\mathbf{b}$ with a high beating level (density of approximately $0.79 \mathrm{~g} / \mathrm{cm}^{3}$ ). The curl values are for fibers with a length between $1.5 \mathrm{and} 3 \mathrm{~mm}$

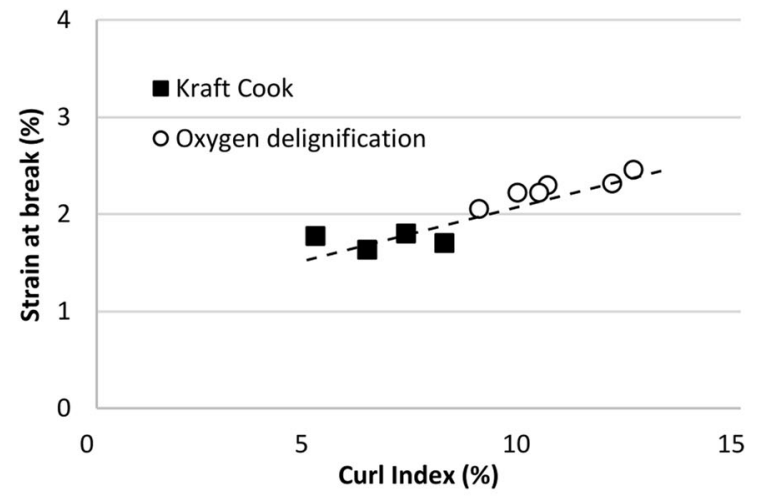

(a)

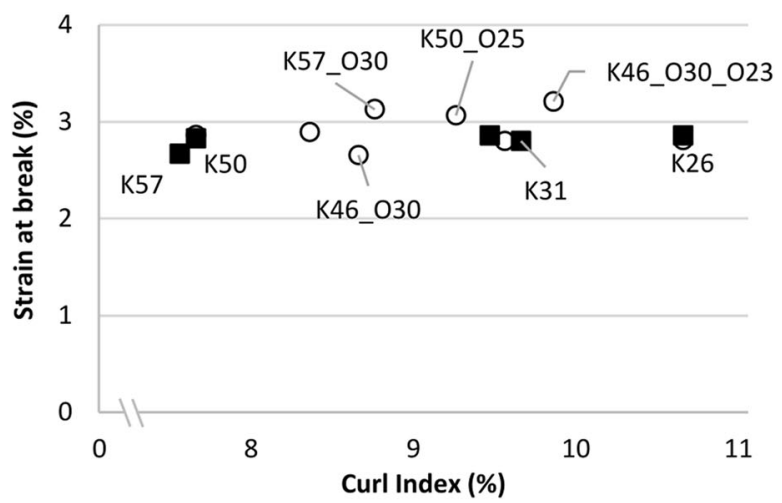

(b)

Fig. 11 Strain at break as a function of curl index for a non-beaten pulps and for $\mathbf{b}$ pulp beaten at 4000 revolutions. The curl values are for fibers with a length between 1.5 and $3 \mathrm{~mm}$

Beating is a successful way to increase the paper elongation by improving fiber-fiber joint strength. Despite the initially greater extent of fiber deformation in the oxygen delignified fibers, they had the same strain at break as the cooked pulps after beating, showing that the deformation is not as important for the elongation behavior as has been expected (Kouko et al. 2019).

Considering the samples with the same kappa number, it seems that the oxygen delignified pulps K57_O30 and K50_O25 had slightly higher elongation values than the cooked pulps K31 and K26 with lower swelling ability. The poorly bonded K46_O30 network fails before the full elongation potential is achieved, whereas the well-bonded K57_O30 network will stand a greater stress and the fibers become more strained before network failure; Fig. 11(b). The extensibility of the fibers is known to be related to the swelling and to the inter-fiber joint strength (Vishtal and Retulainen 2014). The increase in the fiber charges and the beating process can explain the slight increase in the strain at break (Bäckström et al. 2009).

\section{Refining: effect on fiber width}

Figure 12 shows that there was no difference in width between cooked and oxygen delignified pulp fibers, but there was a significant difference between beaten and non-beaten pulps. Both oxygen and cooked pulps, had a lower width than pulps that were beaten at 4000 revolutions, probably due to the fiber collapsing 


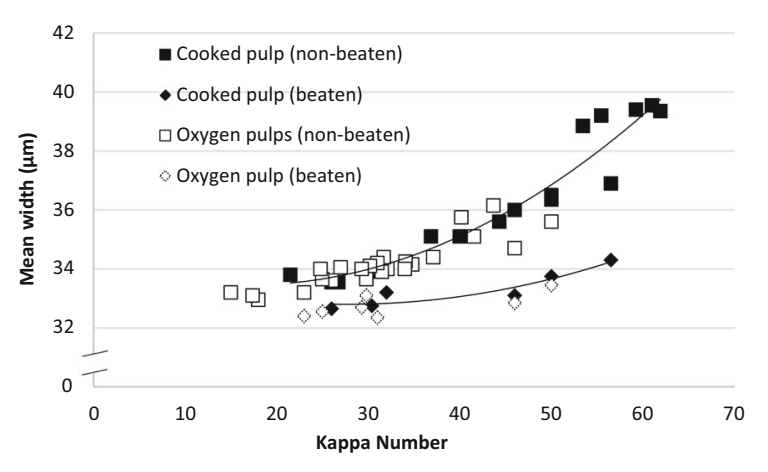

Fig. 12 Mean fiber width of non-beaten pulps and pulps beaten at 4000 revolutions, for fibers with a length of 1.5 and $3 \mathrm{~mm}$

potentiated by the internal fibrillation occurring during the beating process (Motamedian et al. 2019).

\section{Discussion and conclusions}

Previously, it was believed that oxygen delignification always led to a loss of strength (Allison et al. 1998; Joutsimo and Giacomozzi 2015; Rauvanto and Henricson 2009), due to fiber deformation, curl and kinks, loss of strength of the fibers or changes in the network structure. However, it has been shown that oxygen can improve the mechanical strength of paper (Esteves et al. 2020; Snowman et al. 1999; Yang et al. 2003; Zhang et al. 2005) even if fiber deformation occurs. Fiber deformation can be due to an increased fiber vulnerability after cooking and defibration and not to the oxygen delignification (Esteves et. al. 2021). In the kraft process, the wood chips are subjected to less mechanical action than during oxygen delignification and the fibers are not so adaptable to subsequent beating. This can lead to an increase in the curl index during the beating process. On the other hand, fibers that are subjected to oxygen delignification are subjected to a chemical environment and mechanical forces as an individualized fiber, leading to a higher adaptability of the fibers for the subsequent beating. The higher amount of charges and greater swellability will straighten fibers in the beating process to such an extent that they are less deformed than cooked pulp fibers. The fact that the oxygen delignified fibers are more swollen and have higher fiber charges leads to fibers with a higher ductility and the beating process can lead to delamination of the fiber wall (Bäckström et al. 2013). Swelling provides a larger area for fiber- to-fiber contact and leads to a lateral softening that results in a greater conformability (Clark 1969). This does not always result in an increase in tensile strength. The improvement in mechanical strength is only seen when there is also a substantial increase in fiber charges. The refining process is much more efficient in creating external fibrillation, if the fibers are highly charged where the volume can be significantly increased. This can be made possible by increasing the oxygen delignification until a threshold point is achieved.

To conclude:

- The WRV was highly correlated with the fiber charge. At a given charge, kraft cooked and oxygen delignified pulps had the same WRV development in refining, although kraft delignified pulp had a significantly higher kappa number.

- A higher fiber charge leads to a higher WRV and, if the charge is sufficiently high the refining is significantly improved by a greater external fibrillation, increasing the mechanical strength of the paper.

- The refining step seemed to be optimized when performed at extremely high charges in the fibers after oxygen delignification instead of kraft cooked pulp to the same kappa number, suggesting that it would be beneficial to perform shorter kraft cooks and prolonging oxygen delignification.

- The tensile strength development during refining is not determined entirely by either fiber charge or WRV. The lignin content of the pulp is also important. Pulps with a higher lignin content are more rigid and the development of tensile strength by refining was slower and led to less densification of the sheet. At a given kappa number, however, a higher fiber charge resulted in a higher sheet density. Despite the lower density of the high kappa number pulps after kraft cooking, they gave a higher tensile strength at lower beating levels.

- The tensile index was affected by the curl. Higher curl resulted in a lower tensile index both for cooked and oxygen delignified pulps. PFI refining increased the curl of cooked pulp and decreased the curl of oxygen delignified pulp. The kappa number of the pulp had no influence on the development of curl. At a given kappa number, the curl was greater in cooked pulp than in oxygen delignified pulp. Oxygen delignified pulp fibers were more flexible, 
and refining oxygen delignified pulp was more efficient in removing curl and kinks than when refining cooked pulp.

- There was no correlation between Schoper-Riegler value and fiber charges, but refining of the pulp with the highest fiber charge increased the SR value significantly, possibly due to the fibrillation or production of fines.

- Refining increased the curl of cooked pulp and decreased the curl of oxygen delignified pulps.

- The tensile strength was affected by the curl index but the elongation at break for beaten pulps was not be affected.

- Refining reduced the width of fibers, suggesting that the mechanical treatment leads to fiber collapse.

- It would be interesting to study the fines content after the beaten process, in order to understand whether the presence of fiber charges in the beaten process leads to more fines or to more fibrils.

Acknowledgments The authors gratefully acknowledge the STFI's Intressentförening for financial support. The Knut and Alice Wallenberg Foundation, the WWSC Program and the Wood and Pulping Chemistry Research Network (WPCRN) at KTH are gratefully acknowledged for financial support for Dr. Sevastyanova. The authors would also like to acknowledge Dr. Anthony Bristow for the linguistic revision.

Funding Open access funding provided by RISE Research Institutes of Sweden. STFI's Intressentförening.

\section{Declaration}

Conflict of interest There is no conflict to declare.

Informed consent Informed consent was not required due to the retrospective nature of this study.

Open Access This article is licensed under a Creative Commons Attribution 4.0 International License, which permits use, sharing, adaptation, distribution and reproduction in any medium or format, as long as you give appropriate credit to the original author(s) and the source, provide a link to the Creative Commons licence, and indicate if changes were made. The images or other third party material in this article are included in the article's Creative Commons licence, unless indicated otherwise in a credit line to the material. If material is not included in the article's Creative Commons licence and your intended use is not permitted by statutory regulation or exceeds the permitted use, you will need to obtain permission directly from the copyright holder. To view a copy of this licence, visit http://creativecommons.org/licenses/by/4.0/.

\section{References}

Allison R, Ellis M, Kibblewhite R, Duffy G (1998) Effect of mechanical processes on the strength of oxygen delignified kraft pulp. In: proceedings of the 1998 international pulp bleaching conference, Helsinki, Finland, pp 159-166

Barzyk D, Page DH, Ragauskas AJ (1997) Acidic group topochemistry and fiber-to-fiber specific bond strength. J Pulp Pap Sci 23:J59-J61

Bäckström M, Hammar L-Å, Htun M (2009) Beatability and runnability studies of ion-exchanged unbleached kraft pulps on a pilot scale. Nord Pulp Pap Res J 24:94-100

Bäckström M, Melander E, Brännvall E (2013) Study of the influence of charges on refinability of bleached softwood kraft pulp. Nord Pulp Pap Res J 28:588-595

Campbell WB (1959) The mechanism of bonding. Tappi J 42:999-1001

Clark J (1969) Fibrillation free water and fiber bonding. Tappi J 52:335-0

Dang Z, Elder T, Ragauskas AJ (2006) Influence of kraft pulping on carboxylate content of softwood kraft pulps. Ind Eng Chem Res 45:4509-4516

Engstrand P, Sjögren B, Ölander K, Htun M (1991) The significance of carboxylic groups for the physical properties of mechanical pulp fibers. In: Appita 6th international symposium on wood \& pulping chemistry proceedings, Melbourne. pp 75-79

Esteves CVG, Brännvall E, Östlund S, Sevastyanova O (2020) Evaluating the potential to modify pulp and paper properties through oxygen delignification ACS. Omega 5:13703-13711. https://doi.org/10.1021/acsomega. 0c00869

Esteves CV, Sevastyanova O, Östlund S, Brännvall E (2021) Differences and similarities between kraft and oxygen delignification of softwood fibers: effects on chemical and physical properties. Cellulose. https://doi.org/10.1007/ s10570-021-03713-0

Hammar L-Å, Bäckström M, Htun M (2000) Effect of the counterion on the beatability of unbleached kraft pulps. Nord Pulp Pap Res J 15:189-193

Hirn U, Schennach R (2015) Comprehensive analysis of individual pulp fiber bonds quantifies the mechanisms of fiber bonding in paper. Sci Rep 5:1-9

Ingmanson WL, Thode EF (1959) Factors contributing to the strength of a sheet of paper II Relative bonded area. Tappi J 42:83-93

Joutsimo O, Wathén R, Tamminen T (2005) Effects of fiber deformations on pulp sheet properties and fiber strength. Paperi ja puu 87:392

Joutsimo OP, Giacomozzi D (2015) Changes in cell wall structure during kraft processing of Pinus radiata. BioResources 10:2461-2478

Katz S, Beatson RP, Scallon AM (1984) The determination of strong and weak acidic groups in sulfite pulps. Svensk papperstidn 87:48-53

Kouko J, Jajcinovic M, Fischer W, Ketola A, Hirn U, Retulainen E (2019) Effect of mechanically induced micro deformations on extensibility and strength of individual softwood pulp fibers and sheets. Cellulose 26:1995-2012. https://doi. org/10.1007/s10570-018-2163-y 
Laine J (1997) The effect of surface chemical composition and charge on the fibre and paper properties of unbleached and bleached kraft pulps. In: fundamentals of papermaking materials: 11th fundamental research symposium, Cambridge, September 21-26 1997. pp 859-892

Laine J, Stenius P (1997) Effect of charge on the fibre and paper properties of bleached industrial kraft pulps. Paperi ja puu 79:257-266

Lindström T, Carlsson G (1982) The effect of carboxyl groups and their ionic form during drying on the hornification of cellulose fibers. Svensk Papperstidn 85:R146-R151

Mohlin U-B (2002) Industrial refining of unbleached kraft pulps-The effect of $\mathrm{pH}$ and refining intensity Sweden: STFI AB, Swedish Pulp and Paper Research Institute

Mohlin U-B, Alfredsson C (1990) Fibre deformation and its implications in pulp characterization. Nord Pulp Pap Res J 5:172-179

Mohlin U-B, Dahlbom J, Hornatowska J (1996) Fiber deformation and sheet strength. Tappi J 79:105-111

Motamedian HR, Halilovic AE, Kulachenko A (2019) Mechanisms of strength and stiffness improvement of paper after PFI refining with a focus on the effect of fines. Cellulose 26:4099-4124. https://doi.org/10.1007/s10570-019$02349-5$

Niskanen K (2000) Kraft fibers in paper-Effect of beating. In: Kennedy JF, Phillips GO, Williams PA (eds) Cellulosic Pulps, Fibres and Materials. Elsevier, Amsterdam, pp 249-260

Nordström B (2014) Unbleached linerboard kraft pulps with different kappa number (yield)-effects on tensile properties and compression strength with free or restrained drying. Nord Pulp Pap Res J 29:462-467

Nordström B (2015) Initial medium-consistency refining of high-yield softwood kraft pulp-effects on tensile properties and compression strength. Nord Pulp Pap Res J 30:302-307

Paavilainen L (1994) Bonding potential of softwood sulphate pulp fibres. Paperi ja puu 76:162-173

Page DH (1985) The mechanism of strength development of dried pulps by beating. Svensk papperstidn $88:$ R30

Page DH (1989) The beating of chemical pulps-The action and the effects. In: Baker CF, Punton V (eds) Fundamentals of Papermaking, vol 1. FRC, Manchester, pp 1-38. https:// doi.org/10.15376/frc.1989.1.1

Page DH, Seth RS, Jordan BD, Barbe MC Curl, crimps, kinks and microcompressions in pulp fibres: their origin, measurement and significance. In: transactions of the 8th fundamental research symposium, London, UK, 1985. Mechanical Engineering Publications Ltd.: London, pp 183-227
Rauvanto I, Henricson K (2009) Fibre damage in oxygen delignification: Mechanical and chemical interactions. Pulp Pap Sci 35:34-38

Retulainen E (1997) The role of fibre bonding in paper properties. Helsinki University of Technology, Espoo

Scallan A (1983) The effect of acidic groups on the swelling of pulps: a review. Tappi J 66:73-75

Scallan AM, Grignon J (1979) The effect of cations on pulp and paper properties. Svensk papperstidn 82:40-47

Schmied FJ, Teichert C, Kappel L, Hirn U, Bauer W, Schennach R (2013) What holds paper together: nanometre scale exploration of bonding between paper fibres. Sci Rep 3:1-6

Snowman VR, Genco JM, Cole BJ, Kwon HB, Miller WJ (1999) Bond strength of oxygen-delignified kraft pulps. Tappi J 82:103-109

Stone J, Scallan A, Abrahamson B (1971) Influence of beating on cell wall swelling and internal fibrillation. Svensk papperstidn 71:687-694

Van den Akker J, Lathrop A, Voelker M, Dearth L (1958) Importance of fiber strength to sheet strength. Tappi J 41:416-425

Vishtal A, Retulainen E (2014) Boosting the extensibility potential of fibre networks: a review. BioResources 9:7951-8001

Wågberg L (2009) Swelling of fibers. In: Ek M, Gellerstedt G, Henriksson G (eds) Pulp and paper chemistry and technology, vol 3. Walter de Gruyter, Berlin, pp 54-61

Yang R, Lucia L, Ragauskas AJ, Jameel H (2003) Oxygen delignification chemistry and its impact on pulp fibers. J Wood Chem Technol 23:13-29. https://doi.org/10.1081/ WCT-120018613

Zhang DC, Chai X-S, Hou Q, Ragauskas AJ (2005) Characterization of fiber carboxylic acid development during onestage oxygen delignification. Ind Eng Chem Res 44:9279-9285

Zhang DC, Chai X-S, Pu Y, Ragauskas AJ (2007) Lignocellulosic fiber charge enhancement by catalytic oxidation during oxygen delignification. $\mathrm{J}$ Colloid Interf Sci 306:248-254

Zhao C, Zhang H, Zeng X, Li H, Sun D (2016) Enhancing the inter-fiber bonding properties of cellulosic fibers by increasing different fiber charges. Cellulose 23:1617-1628. https://doi.org/10.1007/s10570-016-0941$\mathrm{y}$

Publisher's Note Springer Nature remains neutral with regard to jurisdictional claims in published maps and institutional affiliations. 